\title{
Pulmonary complications after lung resection in the absence of chronic obstructive pulmonary disease: The predictive role of diffusing capacity
}

\author{
Mark K. Ferguson, MD, ${ }^{\mathrm{a}}$ Henning A. Gaissert, MD, ${ }^{\mathrm{b}}$ Joshua D. Grab, $\mathrm{MS},{ }^{\mathrm{c}}$ and Shubin Sheng, $\mathrm{MS}^{\mathrm{c}}$
}

Objective: Diffusing capacity is not routinely used in assessing risk of lung resection, perhaps owing to uncertainty as to whether patients with normal spirometric results require additional evaluation. We determined whether diffusing capacity is predictive of pulmonary complications after lung resection in patients with normal spirometric results.

Methods: We reviewed outcomes of major lung resection in The Society of Thoracic Surgeons General Thoracic Surgery Database from 2002 to 2008 to determine the relationship of diffusing capacity (expressed as percent of predicted) to postoperative pulmonary complications stratified by chronic obstructive pulmonary disease status.

Results: Percent of predicted diffusing capacity was measured in $7891(57 \%)$ patients. There were 3905 women and 3986 men with a mean age of $66.3 \pm 10.6$ years who underwent lobectomy (6904; 87.5\%), bilobectomy (463; 5.9\%), and pneumonectomy (524; 6.6\%). Chronic obstructive pulmonary disease was identified in $2711(34.4 \%)$ patients. Pulmonary complications occurred in $13 \%$, and the operative mortality was $1.9 \%$. Percent of predicted diffusing capacity was strongly associated with the development of pulmonary complications (odds ratio, 1.12 per 10-point decrease; $P<.0001$ ). Decreasing percent of predicted diffusing capacity was incrementally related to an increased incidence of pulmonary complications regardless of chronic obstructive pulmonary disease status. There was no apparent interaction between percent of predicted diffusing capacity and chronic obstructive pulmonary disease status in the predictive model.

Conclusions: Percent of predicted diffusing capacity predicts pulmonary complications after lung resection in patients without chronic obstructive pulmonary disease. We recommend measurement of diffusing capacity in lung resection candidates, regardless of chronic obstructive pulmonary disease, as an important element in the accurate assessment of operative risk. (J Thorac Cardiovasc Surg 2009;138:1297-302)

Pulmonary complications are among the most common causes of postoperative morbidity after major lung resection. They are associated with increased operative mortality and hospital cost. ${ }^{1}$ Although spirometry and diffusing capacity of the lung for carbon monoxide (DLCO) were both shown in the 1950 s to be importantly reduced after major lung resection, ${ }^{2-4}$ the use of DLCo has not become routine in assessing operative risk for major lung resection. In the European Thoracic Surgery Database, $77 \%$ of patients underwent major lung resection without measurement of DLco. ${ }^{5}$ It is not known whether this is owing to lack of access to qualified pulmonary function laboratories, cost concerns, or the impression that patients with normal spirometric results do not require the additional measurement of DLCO.

\footnotetext{
From the University of Chicago, ${ }^{\mathrm{a}}$ Chicago, Ill; the Massachusetts General Hospital, ${ }^{\mathrm{b}}$ Boston, Mass; and the Duke Clinical Research Institute, ${ }^{\mathrm{c}}$ Durham, NC.

Read at the Thirty-fourth Annual Meeting of The Western Thoracic Surgical Association, Kona, Hawaii, June 25-28, 2008.

Received for publication June 14, 2008; revisions received April 16, 2009; accepted for publication May 5, 2009; available ahead of print Sept 27, 2009.

Address for reprints: Mark K. Ferguson, MD, Department of Surgery, 5841 S. Maryland Ave, MC5035, Chicago, IL 60637 (E-mail: mferguso@surgery.bsd.uchicago. edu).

$0022-5223 / \$ 36.00$

Copyright (C) 2009 by The American Association for Thoracic Surgery

doi:10.1016/j.jtcvs.2009.05.045
}

Two recent reports demonstrate that DLCo is an important and independent predictor of postoperative complications after major lung resection, even in patients without chronic obstructive pulmonary disease (COPD). ${ }^{6,7}$ Both reports were based on review of outcomes from single institutions, raising concerns about how generalized the findings and recommendations are. The recent advent of The Society of Thoracic Surgeons (STS) General Thoracic Surgery Database provides an ideal opportunity to explore the utility of DLCo measurement in the general population of patients undergoing major lung resection for cancer. Using the STS database, we sought to determine the relative predictive value of DLCO in patients with and without COPD.

\section{METHODS}

Outcomes of major lung resection in the STS General Thoracic Surgery Database from January 2002 through June 2008 were reviewed. Patients were selected who had a diagnosis of primary lung cancer and who underwent major lung resection (lobectomy, sleeve lobectomy, bilobectomy, or pneumonectomy). Exclusion criteria were as follows: concomitant chest wall resection, extrapleural pneumonectomy, carinal sleeve pneumonectomy, completion pneumonectomy, and emergency or urgent operation. Demographic and surgical information was abstracted from the database for analysis. COPD was defined as $\mathrm{FEV}_{1} / \mathrm{FVC}<0.7$ $\left(\mathrm{FEV}_{1}\right.$, forced expiratory volume in the first second; FVC, forced vital capacity) and $\mathrm{FEV}_{1} \%<80$, which corresponds to moderate to severe COPD by international criteria. ${ }^{8}$ Patients without COPD were classified 


\section{Abbreviations and Acronyms \\ ASA = American Society of Anesthesiolgists \\ $\mathrm{COPD}=$ chronic obstructive pulmonary disease \\ DLCO $=$ diffusing capacity of the lung for carbon monoxide \\ $\mathrm{FEV}_{1}=$ forced expiratory volume in the first second \\ $\mathrm{FVC}=$ forced vital capacity \\ STS $=$ The Society of Thoracic Surgeons}

as "normal" ( $\mathrm{FEV}_{1} / \mathrm{FVC} \geq 0.7$ and $\left.\mathrm{FEV}_{1} \%>80\right)$ or "not normal/no COPD" ' FEV $_{1} / \mathrm{FVC}<0.7$ or $\mathrm{FEV}_{1} \%<80$, but not both). Some categorical variables (performance status, American Society of Anesthesiolgists [(ASA] score) were dichotomized, whereas resection type was organized into 3 categories: lobectomy, bilobectomy or sleeve lobectomy, and pneumonectomy. Staging was done according to the American Joint Commission on Cancer. ${ }^{9}$ The study end point was pulmonary complications, defined as atelectasis necessitating bronchoscopy, pneumonia, adult respiratory distress syndrome, bronchopleural fistula, initial ventilator support necessary for more than 48 hours, tracheostomy, reintubation for any reason, or any other pulmonary complication.

Patients with insufficient data, primarily DLCo (expressed as a percent of predicted), were omitted from the analysis. Univariate analyses were performed by $\chi^{2}$ analysis for categorical variables and the unpaired Student $t$ test for continuous variables. Mulitvariable analyses included logistic regression methods using generalized estimating equations to account for within-site (ie, hospital) correlation of patients. Interaction terms were constructed to explore independence of variables in the models. Continuous data are expressed as mean $\pm \mathrm{SD}$.

A waiver for this study was granted by The University of Chicago Internal Review Board.

\section{RESULTS}

Records were available for 14,160 patients operated on at 107 participating sites during the period of study. Of these, $2.3 \%$ had spirometric data that were considered inaccurate. Of the remaining 13,839 patients, 7891 (57\%) had sufficient DLCo data and were used in the analyses. Criteria for COPD were present in $2711(34.4 \%)$ patients, $2672(33.8 \%)$ patients had normal spirometric data, and 2508 (31.8\%) were classified as not normal/no COPD. There were few clinically important differences between the groups of patients with and without values for Duco (Table 1). Patients with DLCo measurement were more advanced in mean age, more likely to have hypertension and to receive induction therapy, and had higher mean $\mathrm{FVC}$ and $\mathrm{FEV}_{1}$ values. Duco measurement, however, was also associated with a lower mean $\mathrm{FEV}_{1} / \mathrm{FVC}$ ratio and a greater proportion of patients with COPD. Operations in the study group included lobectomy in $6904(87.5 \%)$, sleeve lobectomy or bilobectomy in $463(5.9 \%)$, and pneumonectomy in 524 $(6.6 \%)$. The majority of patients in the study group had $\mathrm{T} 1$ or $\mathrm{T} 2$ tumors $(84.5 \%)$ and no nodal involvement $(69.1 \%)$. The incidence of pulmonary complications in the study group was $13 \%$, and $1.9 \%$ of patients had operative mortality (Table 2). The incidences of pulmonary complications and operative mortality did not differ between groups with and without DLCo measurements.

Univariate analyses identified a number of variables that were associated with pulmonary complications, including age, sex, performance status, ASA class, cardiovascular disease, pulmonary dysfunction, other organ dysfunction, and the extent of the operation (Table 3). Logistic regression analysis identified age, performance status, ASA class, congestive heart failure, renal insufficiency, a recent smoking history, induction therapy, the extent of resection, $\mathrm{FEV}_{1} \%$, and DLCO as significant predictors of pulmonary complications (Table 4). Age, induction therapy, the extent of surgery, and DLCO \% were the preoperative clinical variables most strongly associated with the development of

TABLE 1. Comparison of patient populations with and without measurement of DLCO

\begin{tabular}{|c|c|c|c|}
\hline Parameter & $\begin{array}{l}\text { DLco not measured } \\
\text { (5948 patients) }\end{array}$ & $\begin{array}{l}\text { DLCO measured } \\
\text { (7891 patients) }\end{array}$ & $P$ value \\
\hline Mean age (y) & $65.8 \pm 11.0$ & $66.3 \pm 10.6$ & .018 \\
\hline Male & $3000(50.4 \%)$ & $3986(50.5 \%)$ & .93 \\
\hline $\begin{array}{l}\text { Performance status } \\
0 \text { or } 1\end{array}$ & $5063 / 5427(93.9 \%)$ & $7177 / 7682(93.4 \%)$ & .76 \\
\hline ASA class I to III & $4905 / 5443(90.1 \%)$ & $6860 / 7580(90.5 \%)$ & .46 \\
\hline BMI & $27.2 \pm 5.9$ & $27.2 \pm 6.0$ & .18 \\
\hline Hypertension & $3161 / 5927(53.3 \%)$ & $4383 / 7855(55.8 \%)$ & .004 \\
\hline $\begin{array}{l}\text { Coronary artery } \\
\text { disease }\end{array}$ & $1206 / 5894(20.5 \%)$ & $1633 / 7781(21.0 \%)$ & .45 \\
\hline $\begin{array}{l}\text { Congestive heart } \\
\text { failure }\end{array}$ & $171 / 5880(2.9 \%)$ & $247 / 7743(3.2 \%)$ & .35 \\
\hline Diabetes mellitus & $824 / 5867(14.0 \%)$ & $1122 / 7805(14.4 \%)$ & .58 \\
\hline Renal insufficiency & $129 / 5899(2.2 \%)$ & $192 / 7854(2.4 \%)$ & .32 \\
\hline $\begin{array}{l}\text { Recent smoking } \\
\text { history }\end{array}$ & $1662 / 5911(28.1 \%)$ & $2154 / 7828(27.5 \%)$ & .44 \\
\hline $\begin{array}{l}\text { Preoperative } \\
\text { chemotherapy }\end{array}$ & $408 / 5805(7.0 \%)$ & $633 / 7700(8.2 \%)$ & .01 \\
\hline $\begin{array}{l}\text { Preoperative } \\
\text { radiotherapy }\end{array}$ & $292 / 5864(5.0 \%)$ & $444 / 7703(5.8 \%)$ & .046 \\
\hline $\mathrm{FVC} \%$ & $85.8 \pm 20.6$ & $88.8 \pm 18.1$ & $<.001$ \\
\hline $\mathrm{FEV}_{1} \%$ & $78.8 \pm 21.7$ & $80.3 \pm 20.9$ & .01 \\
\hline $\mathrm{FEV}_{1} / \mathrm{FVC}$ & $0.69 \pm 0.12$ & $0.68 \pm 0.11$ & $<.001$ \\
\hline COPD & $686 / 2165(31.7 \%)$ & $2711 / 7891(34.4 \%)$ & .02 \\
\hline Procedure & & & .31 \\
\hline Pneumonectomy & $357(6.0 \%)$ & $524(6.6)$ & \\
\hline $\begin{array}{l}\text { Bilobectomy/sleeve } \\
\text { lobectomy }\end{array}$ & $356(6.0 \%)$ & $463(5.9 \%)$ & \\
\hline Lobectomy & $5235(88.0 \%)$ & $6904(87.5 \%)$ & \\
\hline $\begin{array}{l}\text { Pulmonary } \\
\text { complications }\end{array}$ & $723 / 5948(12.2 \%)$ & $1028 / 6863(13.0 \%)$ & .13 \\
\hline Operative mortality & $130 / 5948(2.2 \%)$ & $152 / 7891(1.9 \%)$ & .29 \\
\hline
\end{tabular}


TABLE 2. Incidence of pulmonary complications

\begin{tabular}{llr}
\hline \multicolumn{1}{c}{ Category } & Affected & Percent \\
\hline Any pulmonary complication & $1028 / 7891$ & 13.0 \\
Atelectasis requiring bronchoscopy & $321 / 7828$ & 4.1 \\
Pneumonia & $326 / 7826$ & 4.2 \\
Adult respiratory distress & $97 / 7815$ & 1.2 \\
$\quad$ syndrome (ARDS) & & \\
Bronchopleural fistula & $34 / 7812$ & 0.4 \\
Air leak $>5$ d & $798 / 7790$ & 10.2 \\
Initial ventilator support $>48 \mathrm{~h}$ & $50 / 7816$ & 0.6 \\
Reintubation & $282 / 7821$ & 3.6 \\
Tracheostomy & $101 / 7819$ & 1.3 \\
Other pulmonary complication & $387 / 7824$ & 4.9 \\
\hline
\end{tabular}

these complications $(P<.0001$ for each). After addition of an interaction variable to explore the relationship between DLCO and COPD status, the strongest predictors of pulmonary complications (including DLCO \%) were unchanged, indicating COPD status did not influence the predictive ability of DLCO \% with regard to pulmonary complications. A parsimonious model of pulmonary complications was developed using backward selection $(P=.05)$ and accounting for interactions between $\mathrm{DLCO}_{\%}, \mathrm{FEV}_{1} \%$, and $\mathrm{FVC} \%$. Independent predictors of pulmonary complications and their odds ratios were similar to the nonparsimonious model. The variables with the greatest statistical significance were age, induction therapy, $\mathrm{FEV}_{1} \%$, DLCO \%, extent of resection, and a recent smoking history.

The incidence of DLCO \% less than 60 was $25.7 \%$ overall and was $12.4 \%, 26.3 \%$, and $42.3 \%$ in the normal, not nor$\mathrm{mal} / \mathrm{no}$ COPD, and COPD groups, respectively. Figure 1 illustrates the incidence of pulmonary complications by DLCO group for patients related to COPD status. The frequency of pulmonary complications increased markedly as DLCO \% decreased $(P<.001$ for all patients and for each COPD status group). At the extremes of DlCO (DLCO $\%>90$ or DLCO $\%<$ 60 ), there were no differences in the risk of pulmonary complications within each COPD status category. However, for the DLCO \% categories 60 to 74 and 75 to 89 , there was a significant, increasing risk of pulmonary complications progressing from patients with normal spirometric data to those with $\operatorname{COPD}(P=.003$ for each $)$.

\section{COMMENT}

The ability to predict complications after an operation as common as major lung resection has important ramifications for patients, caregivers, medical research, and the health care industry. Accurate predictive models can enhance communication between patients and their surgeons, may indicate when preoperative intervention is indicated to reduce risk, can help determine whether parenchyma-sparing procedures rather than anatomic lobectomy are appropriate, and may
TABLE 3. Univariate analysis of factors associated with pulmonary complications

\begin{tabular}{|c|c|c|c|}
\hline Parameter & $\begin{array}{c}\text { No complications } \\
\text { (6863 patients) }\end{array}$ & $\begin{array}{l}\text { Complications } \\
\text { (1028 patients) }\end{array}$ & $P$ value \\
\hline Mean age (y) & $66.1 \pm 10.6$ & $67.7 \pm 10.3$ & $<.001$ \\
\hline Male & $49.0 \%$ & $52.8 \%$ & .022 \\
\hline \multicolumn{4}{|l|}{$\begin{array}{l}\text { Zubrod performance } \\
\text { status }\end{array}$} \\
\hline 0 & $44.9 \%$ & $40.4 \%$ & $<.001$ \\
\hline 1 & $49.0 \%$ & $49.4 \%$ & \\
\hline 2 & $4.8 \%$ & $8.2 \%$ & \\
\hline 3 or 4 & $1.3 \%$ & $2.0 \%$ & \\
\hline \multicolumn{4}{|l|}{ ASA class } \\
\hline I & $1.8 \%$ & $0.7 \%$ & $<.001$ \\
\hline II & $24.1 \%$ & $15.3 \%$ & \\
\hline III & $65.3 \%$ & $69.8 \%$ & \\
\hline IV or $\mathrm{V}$ & $8.8 \%$ & $14.2 \%$ & \\
\hline BMI & $27.3 \pm 5.8$ & $26.8 \pm 5.8$ & .002 \\
\hline Hypertension & $55.2 \%$ & $59.5 \%$ & .011 \\
\hline $\begin{array}{l}\text { Coronary artery } \\
\text { disease }\end{array}$ & $20.2 \%$ & $26.0 \%$ & $<.001$ \\
\hline $\begin{array}{l}\text { Congestive heart } \\
\text { failure }\end{array}$ & $2.8 \%$ & $5.8 \%$ & $<.001$ \\
\hline Diabetes mellitus & $13.9 \%$ & $17.5 \%$ & .003 \\
\hline Renal insufficiency & $2.1 \%$ & $4.4 \%$ & $<.001$ \\
\hline $\begin{array}{l}\text { Recent smoking } \\
\text { history }\end{array}$ & $26.7 \%$ & $33.0 \%$ & $<.001$ \\
\hline $\begin{array}{l}\text { Preoperative } \\
\text { chemotherapy }\end{array}$ & $7.8 \%$ & $11.3 \%$ & $<.001$ \\
\hline $\begin{array}{l}\text { Preoperative } \\
\text { radiotherapy }\end{array}$ & $5.3 \%$ & $8.6 \%$ & $<.001$ \\
\hline $\mathrm{FVC} \%$ & $89.2 \pm 18.1$ & $86.1 \pm 17.8$ & $<.001$ \\
\hline $\mathrm{FEV}_{1} \%$ & $81.1 \pm 20.9$ & $75.0 \pm 19.8$ & $<.001$ \\
\hline $\mathrm{FEV}_{1} / \mathrm{FVC}$ & $0.68 \pm 0.11$ & $0.66 \pm 0.12$ & $<.001$ \\
\hline \multicolumn{4}{|l|}{ COPD status } \\
\hline Normal spirometry & $35.3 \%$ & $23.9 \%$ & $<.001$ \\
\hline Not normal/no COPD & $31.8 \%$ & $31.8 \%$ & \\
\hline COPD & $32.9 \%$ & $44.3 \%$ & \\
\hline DLCO $\%$ & $75.0 \pm 22.2$ & $67.4 \pm 20.5$ & $<.001$ \\
\hline \multicolumn{4}{|l|}{ Procedure } \\
\hline Pneumonectomy & $6.7 \%$ & $6.1 \%$ & $<.001$ \\
\hline $\begin{array}{l}\text { Bilobectomy/ } \\
\text { sleeve lobectomy }\end{array}$ & $5.5 \%$ & $8.5 \%$ & \\
\hline Lobectomy & $87.8 \%$ & $85.4 \%$ & \\
\hline
\end{tabular}

$A S A$, American Society of Anesthesiology; $F V C$, forced vital capacity; $F E V_{l}$, forced expiratory volume in the first second; $B M I$, body mass index; recent smoking history, quit cigarette use less than 30 days before the operation; $C O P D$, chronic obstructive pulmonary disease defined as $\mathrm{FEV}_{1} / \mathrm{FVC}<0.7$ and $\mathrm{FEV}_{1} \%<80$; normal spirometry, $\mathrm{FEV}_{1} / \mathrm{FVC} \geq 0.7$ and $\mathrm{FEV}_{1} \%>80 ; D L C O$, diffusing capacity of the lung for carbon monoxide.

improve patient selection. Such models also permit risk stratification for quality improvement and clinical research and allow improved allocation of limited clinical resources.

Risk modeling for major lung resection is a burgeoning and increasingly complex field. Until recently, relatively small databases that were usually based at a single institution 
TABLE 4. Logistic regression analysis of pulmonary complications

\begin{tabular}{lcccc}
\hline \multicolumn{1}{c}{ Parameter } & Odds ratio Lower CI & Upper CI $\boldsymbol{P}$ value \\
\hline Age & 1.01 & 1.01 & 1.02 & $<.0001$ \\
Male & 1.13 & 0.97 & 1.32 & .13 \\
Performance status $\geq 2$ & 1.56 & 1.10 & 2.21 & .014 \\
ASA class IV or V & 1.26 & 1.04 & 1.51 & .017 \\
Hypertension & 1.01 & 0.88 & 1.17 & .84 \\
Coronary artery disease & 1.11 & 0.93 & 1.34 & .25 \\
Congestive heart failure & 1.58 & 1.20 & 2.10 & .0014 \\
Diabetes mellitus & 1.18 & 0.98 & 1.41 & .079 \\
Renal insufficiency & 1.53 & 1.10 & 2.15 & .012 \\
Recent smoking history & 1.30 & 1.14 & 1.50 & .0001 \\
Preoperative chemotherapy & 1.51 & 1.27 & 1.8 & $<.0001$ \\
$\quad$ and/or radiotherapy & & & & \\
FVC\% & 1.00 & 1.00 & 1.01 & .22 \\
FEV $\%$ & 0.99 & 0.98 & 1.00 & .005 \\
Spirometry not normal/no & 1.09 & 0.91 & 1.31 & .36 \\
$\quad$ COPD & & & & \\
COPD & 1.16 & 0.94 & 1.43 & .16 \\
DLCO\% (10 point decrease) & 1.12 & 1.09 & 1.16 & $<.0001$ \\
Pneumonectomy & 0.92 & 0.71 & 1.20 & .56 \\
Bilobectomy or sleeve & 1.62 & 1.28 & 2.06 & $<.0001$ \\
$\quad$ lobectomy & & & & \\
\hline
\end{tabular}

CI, Confidence interval; ASA, American Society of Anesthesiology; recent smoking history, quit cigarette use less than 30 days before the operation; $C O P D$, chronic obstructive pulmonary disease defined as $\mathrm{FEV}_{1} / \mathrm{FVC}<0.7$ and $\mathrm{FEV}_{1} \%>80 ; D L C O$, diffusing capacity of the lung for carbon monoxide.

provided limited insight into risk prediction. Models based on these data were characterized by poor predictive ability because of limited statistical power, missing clinical variables, or small numbers of complications. Their applicability to more general populations was therefore questioned. The recent creation of national and international databases for thoracic surgery, such as the European Thoracic Surgery Database, Epithor (French Society of Thoracic and CardioVascular Surgery), and the STS General Thoracic Surgery Database, opens the field to new possibilities of risk prediction and improved outcomes for major lung resection.

As these databases grow and predictive modeling based on their data improves, how will this information be used? It is interesting to note how the development of other models of risk of pulmonary surgery has affected surgeon behavior in the recent past. Until the 1990s, models for risk of major lung resection accounted for only $12 \%$ to $22 \%$ of operative mortality. ${ }^{10,11}$ DeCo was identified in 1988 as a strong, independent predictor of morbidity after major lung resection. ${ }^{12}$ The utility of Duco in assessing risk was confirmed by a number of other authors. ${ }^{13-16}$ Despite the recognition of DLCO as the single strongest predictor of pulmonary morbidity and operative mortality after major lung resection, surgeons have been slow to adopt its use in the routine assessment of patients for lung resection. In the European Thoracic Database, less than $25 \%$ of patients undergoing lung resection had a preoperative Duco measured. ${ }^{5}$ In the

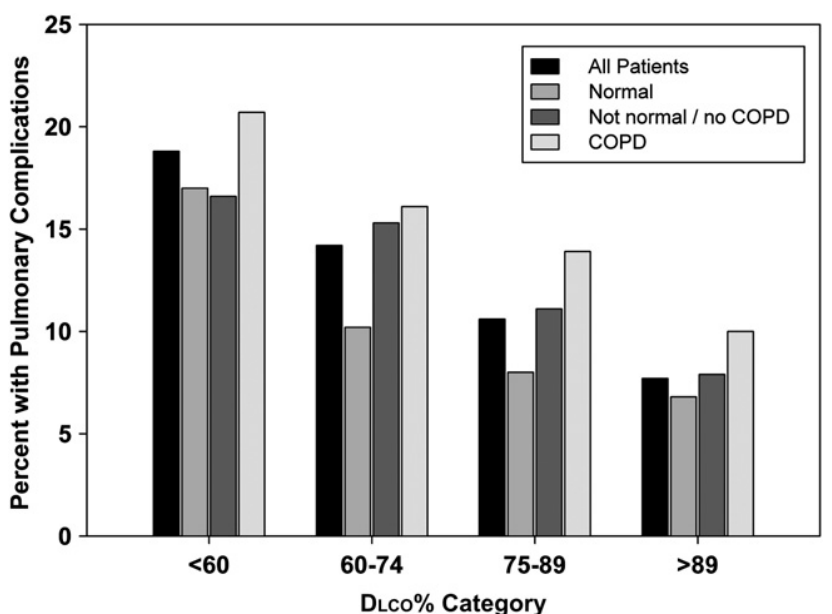

FIGURE 1. Risk of pulmonary complications relative to diffusing capacity $(D L C O)$ and chronic obstructive pulmonary disease (COPD) status.

STS General Thoracic Surgery Database, we found that DLCo was reported for fewer than $60 \%$ of patients undergoing major lung resection. This attitude is supported by published algorithms that do not include Deco as an initial screening measure for lung resection candidates. ${ }^{17,18}$

Possible reasons for omitting DLCO as part of routine preoperative evaluation include limited access to testing facilities, concerns about cost-effectiveness, lack of awareness of the predictive ability of this test, use of other predictive tests such as exercise capacity in lieu of DLCO, perceived lack of impact on clinical recommendations, and perceived lack of utility in the setting of normal spirometry. This study explored the question of whether Deco has predictive ability for pulmonary complications after major lung resection in patients with normal spirometric results. Recent publications from single institutional data found that risk associated with DLCo was independent of whether patients had COPD. ${ }^{6,7}$ Because findings from such reports may not be applicable to the general population, in this study a national database was queried to determine whether DLCO independently predicts risk regardless of COPD status.

The data for this study came from 107 centers that may represent a self-selected group of surgeons and medical centers with interest in tracking clinical activity and outcomes. Reasons for why some patients had DLCO reported and others did not are unclear; the population of patients with Duco measured was somewhat older with a higher incidence of risk factors such as hypertension, induction therapy, and COPD. Interestingly, the patients without DLCO measurements had worse spirometric data, suggesting that the decision to measure DLCo is not based on the clinical impression or actual measurement of lung volumes and flows. Outcomes of surgery were quite good, with $13 \%$ of patients having postoperative pulmonary complications and only $1.9 \%$ of patients having operative mortality. We found that, regardless of COPD status, DLCO was a strong 
preoperative clinical predictor of pulmonary complications after major lung resection. The results are similar to those reported from independent centers. ${ }^{6,7}$ The results of this study confirm the general applicability of using DLCo as a routine measure of risk in the preoperative assessment of lung resection candidates regardless of COPD status.

There are several potential weaknesses in this study. The data set may not be reflective of the general population of patients who undergo major lung resection in the United States. Because the STS General Thoracic Surgery Database does not have an auditing feature, whether the data are accurate and reflect all of the patients treated at participating sites are unknown. A large number of patients were excluded from this study because information on DLCO was lacking. Whether this information was lacking because it was never obtained or because it was not entered into the database is not certain. A number of differences existed between the groups of patients with and without DLCO measurements, some of which were important in the predictive models for pulmonary complications.

In summary, we found that DLCO is an independent and strong predictor of the risk of pulmonary complications in patients undergoing major lung resection for cancer and that this predictive ability exists regardless of COPD status. The lack of Dico measurement was associated with worse spirometric results, suggesting the possibility that physicians who do not measure DLCo routinely before major lung resection may have indications for its measurement other than or in addition to spirometric findings. Surgeons who elect to forego measurement of DLCO on the basis of the absence of classic findings of COPD will fail to identify an important abnormality in this factor in up to $25 \%$ of patients. We recommend measurement of DLCO in candidates for lung resection as an important element in the accurate assessment of operative risk.

\section{References}

1. Wang J, Olak J, Ultmann RE, Ferguson MK. Assessment of pulmonary complications after lung resection. Ann Thorac Surg. 1999;67:1444-7.

2. Bates DV, Mcllroy MB. Respiratory function after pneumonectomy. Thorax. 1956;11:303-11.

3. Burrows B, Harrison RW, Adams WE, Humphreys EM, Long ET, Reimann AF. The postpneumonectomy state: clinical and physiologic observations in thirty-six cases. Am J Med. 1960;28:281-97.

4. Dietiker F, Lester W, Burrows B. The effects of thoracic surgery on the pulmonary diffusing capacity. Am Rev Respir Dis. 1960;81:830-8.

5. Berrisford R, Brunelli A, Rocco G, Treasure T, Utley M. Audit and Guidelines Committee of the European Society of Thoracic Surgeons; European Association of Cardiothoracic Surgeons. The European Thoracic Surgery Database project: modeling the risk of in-hospital death following lung resection. Eur $J$ Cardiothorac Surg. 2005;28:306-11.

6. Brunelli A, Refai MA, Salati M, Sabbatini A, Morgan-Hughes NJ, Rocco G. Carbon monoxide lung diffusion capacity improves risk stratification in patients without airflow limitation: evidence for systematic measurement before lung resection. Eur J Cardiothorac Surg. 2006;29:567-70.

7. Ferguson MK, Vigneswaran WT. Diffusing capacity predicts postoperative morbidity after major lung resection in patients without obstructive pulmonary disease. Ann Thorac Surg. 2008;85:1158-65.
8. Rabe KF, Hurd S, Anzueto A, Barnes PJ, Buist SA, Calverley P, et al. Global initiative for chronic obstructive lung disease. Global strategy for the diagnosis, management, and prevention of chronic obstructive pulmonary disease: GOLD executive summary. Am J Respir Crit Care Med. 2007;176:532-55.

9. American Joint Committee on Cancer. AJCC staging manual. 6th ed. New York: Springer; 2002.

10. Kohman LJ, Meyer JA, Ikins PM, Oates RP. Random versus predictable risks of mortality after thoracotomy for lung cancer. J Thorac Cardiovasc Surg. 1986;91:551-4

11. Licker M, de Perrot M, Höhn L, Tschopp JM, Robert J, Frey JG, et al Perioperative mortality and major cardio-pulmonary complications after lung surgery for non-small cell carcinoma. Eur J Cardiothorac Surg. 1999;15:314-9.

12. Ferguson MK, Little L, Rizzo L, Popovich KJ, Glonek GF, Leff A, et al. Diffusing capacity predicts morbidity and mortality after pulmonary resection. $J$ Thorac Cardiovasc Surg. 1988;96:894-900.

13. Ferguson MK, Reeder LB, Mick R. Optimizing selection of patients for major lung resection. J Thorac Cardiovasc Surg. 1995;109:275-83.

14. Markos J, Mullan BP, Hillman DR, Musk AW, Antico VF, Lovegrove FT, et al. Preoperative assessment as a predictor of mortality and morbidity after lung resection. Am Rev Respir Dis. 1989;139:902-10.

15. Pierce RJ, Copland JM, Sharpe K, Barter CE. Preoperative risk evaluation for lung cancer resection: predicted postoperative product as a predictor of surgical mortality. Am J Respir Crit Care Med. 1994;150:947-55.

16. Alam N, Park BJ, Wilton A, Seshan VE, Bains MS, Downey RJ, et al. Incidence and risk factors for lung injury after lung cancer resection. Ann Thorac Surg. 2007; 84:1085-91.

17. Colice GL, Shafazand S, Griffin JP, Keenan R, Bolliger CT. Physiologic evaluation of the patient with lung cancer being considered for resectional surgery. ACCP evidenced-based clinical practice guidelines (2nd edition). Chest. 2007; 132:161S-77.

18. Loewen GM, Watson D, Kohman L, Herndon JE 2nd, Shennib H, Kernstine K et al. Cancer and Leukemia Group B. Preoperative exercise VO2 measurement for lung resection candidates: results of Cancer and Leukemia Group B Protocol 9238. J Thorac Oncol. 2007;2:619-25.

\section{Discussion}

Dr Kemp Kernstine (Duarte, Calif). This is a very important study using the STS database, our database, to demonstrate that the DLCo measurement is correlated with complications after lung resection. This correlation was not solely in patients with COPD, but in patients without COPD as well. What your findings tell us is that DLCo should be measured in all patients whether they have COPD or not, because DLCO independently is correlated with the postoperative lung resection complication rate.

I have a couple of questions or comments. Currently, the cardiac and congenital heart surgery databases have a quality assurance system that is a component of each and the thoracic database does not. Do you think that this might affect your results?

Dr Ferguson. It is true that there can be concerns raised by the quality of the data submitted and the selection of data submitted, and we have no way of assessing that. I think it is appropriate to keep those concerns in mind when interpreting the data and the results of our analysis.

Dr Kernstine. Do you recommend then that we should encourage the STS to have a quality assurance system in our thoracic data base?

Dr Ferguson. Absolutely.

Dr Kernstine. Then is the DLco sufficiently standardized across hospitals to make a generalized recommendation that all thoracic surgeons should be performing DLco routinely?

Dr Ferguson. It is a bit of an issue. We have found anecdotally that the occasional patient comes to us with marginal DLCo and when we measure it, it is actually a little bit better. There are a number of potential explanations for that. One is that there are differences in 
techniques or reliability of results between institutions; in addition, some patients have had improvement, for example, in the pneumonia that they presented with to the outside physicians that led to the investigation for possible lung cancer, resulting in an improved DLco on remeasurement. At least a couple of studies have performed repeated measurements on healthy patients over time, demonstrating that, on average, the difference in DLco measurement was about 1 percentage point. I think, in general, measurements of DLCO are very reliable. It is not effort related on the part of the patient and it is not subject to interpretation by someone who is reporting the results, so on the basis of that I think it is very reliable.

Dr David Follette (Sacramento, Calif). Dr Ferguson, I completely agree with your conclusions. I do have 3 questions for you.

In a patient with COPD, it is not only DLCo but the corrected Dico. Is there any way through the database that you can tell whether these were just the numbers or whether they were the corrected numbers, because it can make a difference in a COPD population.

Dr Ferguson. It does make a difference and there is no way of telling in the database which it is. If there is a difference, it is primarily related to hemoglobin of the patient and generally gets better if you use the corrected value than the uncorrected value, but we have no way of distinguishing which value was reported.

Dr Follette. I found that the second and more useful test, especially coupled with the DLCO, is the carbon dioxide level on a blood gas. A slight carbon dioxide retention and marked depression in DLCo, in my view, is the highest risk pulmonary resection candidate that I deal with. In the database, do they report blood gas data and did you happen to correlate $\mathrm{PCO}_{2}$ levels with the DCLO?

Dr Ferguson. That is a good question and I agree with your general assessment, but I do not recall whether there were blood gas values. Certainly we did not perform any correlation between those two. In my own institution, for example, we probably get blood gas information on only about $30 \%$ of patients, so it is not done routinely.

Dr Follette. I know you did not present it, but I would like your guideline as to what DLco level puts a big red flag up in Chicago. I have used one that is less than $40 \%$ with the red flag up for me. The data you presented only showed a 10-point drop from normal. What guideline do you use before you tell the patient and the referring doctors that this is a very high-risk patient?

Dr Ferguson. I try to be cautious when I am talking about specific numbers. In Alex Brunelli's study, they used a predicted postoperative DLCO cutoff of $40 \%$ for distinguishing high-risk patients. That is what we use in general to distinguish between much higher risk than so-called average risk, but it is really incremental all the way. We will go so far as to operate on patients with a postoperative predicted DLCO of maybe $30 \%$ if they seem otherwise pretty vigorous. Everything else has to be taken into account as well as this one number.

Dr Carolyn Reed (Charleston, SC). I think that also pertains to my question. A couple weeks ago we had a patient with $\mathrm{FVC} / \mathrm{FEV}_{1}$ $80 \%$ of predicted, Duco less than $40 \%$ of predicted, maximum oxygen consumption 20 , and the patient had to have a lobectomy to get the cancer out. Would you offer that patient a lobectomy?

Dr Ferguson. Given that DLCo, exercise testing is the additional test I would do, and if that was as good as 20 , yes, I would go with the lobectomy.

Dr Richard Whyte (Stanford, Calif). Dr Ferguson, I have 1 question. You used the term a couple of times that the DLCO was the strongest predictor of increased morbidity. You looked at the $P$ value on that. The $P$ value was very low, but you had other issues there that had a much higher relative risk that were still highly statistically significant. I am wondering why you say this is the most sensitive or this is the least likely to be a random predictor. I would say that perhaps it is not the most important predictor of a bad outcome. Could you comment on that?

Dr Ferguson. I am not a statistician. The $P$ value is substantially less than .0001 , and that is the only reason we say it is the strongest predictor. In our work with our own database in doing backward elimination multivariable analysis, it does arise oftentimes as the only predictor because most of those other things fall out. You have to be a little careful about looking at the odds ratios and comparing them because they are based on a variety of different incremental changes for continuous variables. Somehow, those have to be matched up to enable a head-to-head comparison. What we have elected to do sometimes is to measure effects of a 10-year change in age, a 10-point difference in DLCO, and so on. Whether those changes are equal to a 1-point increase in creatinine or to a change from no hypertension to hypertension is very hard to determine.

Dr Tara Karamlou (Portland, Ore). If I understand your findings, you advocate that DLCo is able to be generalized to the entire population. Yet in one of your earlier slides, you showed that induction chemotherapy and radiotherapy as well as, I believe, mortality, were significantly different although you mention not importantly different from a clinical perspective between the patients who had Dlco measured and the subgroup who did not. Can you defend that statement? Could it be more accurate to say that DLCo might be more useful in patients who perhaps are going to be getting neoadjuvant therapy or within the subgroup where you are actually measuring it from your study?

Dr Ferguson. We do not have numbers of 5.5 million as in the cardiac database, but 5500 patients is a large enough group of patients to demonstrate statistically significant differences between the DlCo and no Dlco groups but not important clinical differences. For example, there is difference in $\mathrm{FEV}_{1}$, but it was only 2 percentage points. I do think, though, it is important that we focus on DLCO measurement in patients undergoing induction therapy, because a number of people have demonstrated a substantial decrease in DLCo as a result of induction chemotherapy and radiation therapy. In our population, we measure DLCO, sometimes on multiple occasions, until the DLCo gets back toward normal before we will subject them to surgery. 